\title{
The relative influence of abundance and priority effects on colonization success in a coral-reef fish
}

\author{
Shane W. Geange ${ }^{1,2} \cdot$ Davina E. Poulos ${ }^{3} \cdot$ Adrian C. Stier $^{4} \cdot$ Mark I. McCormick $^{3}$
}

Received: 28 May 2016/ Accepted: 12 September 2016

(C) Springer-Verlag Berlin Heidelberg 2016

\begin{abstract}
The sequence of species colonization is increasingly recognized as an important determinant of community structure, yet the significance of sequence of arrival relative to colonizer abundance is seldom assessed. We manipulated the magnitude and timing of coral-reef fish settlement to investigate whether the competitive dominance of early-arriving Ambon damselfish (i.e., a priority effect) decreased in strength with increasing abundance of late-arriving lemon damselfish. Sequence of arrival had a stronger effect on survival than the number of competing individuals. Relative to when both species arrived simultaneously, lemon damselfish were less aggressive, avoided competitive interactions more frequently and experienced depressed survival when they arrived later than Ambon damselfish, with these effects occurring independently of lemon damselfish abundance. These results suggest priority effects are more important than colonizer abundance and should motivate the
\end{abstract}

Communicated by Ecology Editor Dr. Stuart A. Sandin

Electronic supplementary material The online version of this article (doi:10.1007/s00338-016-1503-3) contains supplementary material, which is available to authorized users.

Shane W. Geange

sgeange@ doc.govt.nz

1 School of Biological Sciences, Victoria University of Wellington, Wellington, New Zealand

2 Department of Conservation, Wellington, New Zealand

3 Department of Marine Biology and Aquaculture, ARC Centre of Excellence for Coral Reef Studies, James Cook University, Townsville, QLD, Australia

4 Department of Ecology, Evolution, and Marine Biology, University of California, Santa Barbara, CA, USA integration of priority effects into future studies of density dependence to determine their relative importance.

Keywords Competition · Coral-reef fish · Damselfish . Density dependence $\cdot$ Pomacentrus $\cdot$ Settlement

\section{Introduction}

Priority effects are increasingly recognized as an important determinant of alternative stable states (Fukami et al. 2010; Fukami 2015) and species coexistence via the storage effect (Chesson 2003). Yet the importance of priority effects relative to other processes governing community structure is seldom assessed. Priority effects occur in concert with fluctuations in the number of young-of-year arriving at a site due to environmental and demographic stochasticity (Lande et al. 2003; Wilson and Lundberg 2006). These numeric fluctuations have been advocated as a major determinant of population and community structure (Gaines and Roughgarden 1985; Foster and Tilman 2003). For example, competitively inferior species can overwhelm competitively superior species simply through numeric abundance (i.e., a 'mass effect'; Leibold et al. 2004). Ecological theory predicts that variable colonizer abundance and priority effects can have significant impacts on the transient dynamics of ecological systems (Fukami and Nakajima 2011). Such transient dynamics may operate on time scales relevant to conservation and management actions (Collie et al. 2013); however, the short-term influence of priority effects, variation in colonizer abundance and their relative contribution to population and community structure have seldom been empirically evaluated in demographically open systems. 
A coral-reef fish assemblage is a good system for examining short-term inhibitory priority effects. Recent work has shown that individual survival of reef fish settlers can depend on the timing of priority effects (Geange and Stier 2009) and that the strength of priority effects can vary dramatically within populations (Almany 2003; Munday 2004; Geange and Stier 2009; Poulos and McCormick 2014, 2015) and between habitats (Geange and Stier 2010; Adam 2011). However, these studies need to be reconciled against often large variation in settler abundance and earlier work showing that the abundance of settlers can determine their persistence by influencing density-dependent interactions (e.g., Steele 1997; Shima 2001; Shima and Osenberg 2003). Here, we factorially manipulated the abundance and sequence of settlement-stage damselfish arrival onto patch reefs to assess their relative contribution to reef fish survival.

\section{Methods}

We conducted this study in January 2015 in the lagoon of Lizard Island, Great Barrier Reef $\left(41^{\circ} 41.23^{\prime} \mathrm{S}\right.$, $\left.145^{\circ} 27.17^{\prime} \mathrm{E}\right)$, using a grid of 42 coral patch reefs consisting of a 50:50 mixture of live and dead Pocillopora damicornis with a volume of approximately $0.07 \mathrm{~m}^{3}$. Below we provide a brief overview of our experimental methodology; for a full description, see electronic supplementary material.

Due to the lack of settlement-stage Ambon damselfish (Pomacentrus amboinensis) captured in light traps, our experimental design focused on the effects of Ambon damselfish (11.32 $\pm 0.34 \mathrm{~mm} \mathrm{SL}[$ mean $\pm \mathrm{SD}])$ on lemon damselfish (P. moluccensis) (11.30 $\pm 0.35 \mathrm{~mm} \mathrm{SL})$ rather than a fully reciprocal experimental design. We experimentally manipulated the abundance and time of arrival of settlement-stage lemon damselfish relative to settlementstage Ambon damselfish in four treatments: (1) low settler abundance without a priority effect (two Ambon and two lemon damselfish introduced simultaneously); (2) low settler abundance with a priority effect (two Ambon damselfish introduced $3 \mathrm{~h}$ before two lemon damselfish individuals); (3) high settler abundance without a priority effect (two Ambon and six lemon damselfish introduced simultaneously); and (4) high settler abundance with a priority effect (two Ambon damselfish introduced $3 \mathrm{~h}$ before six lemon damselfish). Simulated settlement pulses of 4-8 individuals are representative of the numbers of post-settlement fishes observed on reefs of this size. A 3-h 'priority period' is ecologically relevant since reef fishes settle over several hours overnight (Dufour and Galzin 1993; Holbrook and Schmitt 1997) and competitive interactions are strongest in the hours immediately following settlement (McCormick 2009; Poulos and McCormick 2014). The sizes of fish added to each reef did not differ by more than $0.3 \mathrm{~mm}$ SL. Each fish was tagged below the dorsal fin with subcutaneous fluorescent elastomer (VIE; Northwest Marine Technology, Shaw Island, WA, USA), and on each reef one individual of each species was tagged a different color and acted as the focal individual for behavioral and survival analysis. We ran the experiment in five temporal blocks between 21 and 28 January 2015. Because temporal blocks overlapped, replicates were randomized across available reefs within the grid of 42 patch reefs, yielding 13 replicates for treatments 1 and 2, 11 replicates for treatment 3 and 12 replicates for treatment 4 .

To understand the mechanisms underlying the strength of variation in colonizer abundance and priority effects, we conducted 3-min behavioral observations approximately $20 \mathrm{~min}$ after fish were added to reefs, recording five response variables for the lemon damselfish that interacted the most frequently with other individuals: (1) the number of displays; (2) the number of chases; (3) the number of avoidances; (4) the distance ventured from the reef; and (5) relative height on the reef. Because there were strong correlations between chases and displays, we used principal components analysis (PCA) to create a composite aggression score. PCA 1 accounted for $60 \%$ of the total variation in aggressive interactions and was driven by high positive loadings of total displays and chases $(71 \%)$. Thus, we interpret PCA 1 as a gradient of overall aggression.

We surveyed reefs at approximately 0800, 1200 and $1600 \mathrm{hrs}$ for $3 \mathrm{~d}$ after we introduced fish, recording survival of all individuals and removing any new, non-tagged Ambon or lemon damselfish settlers using eugenol and hand nets. We used Cox proportional hazard regression (Cox 1972) to model survival against time of arrival, the abundance of lemon damselfish settlers and their interaction. A strata term in the model was included to account for temporal block. We right-censored data, used the Efron approximation to handle tied data, used partial likelihood to derive regression coefficients and converted these into estimated changes in mortality rate $(\mathrm{CMR})$ by subtracting 1 from the hazard ratio and multiplying by 100 . We used Schoenfeld residuals scaled by the Kaplan-Meier estimate to test the assumption of proportional hazards and DFBETA values to test for influential data. We selected a best-fit model based on Chi-squared tests that omitted an interaction between time of arrival and abundance $(P=0.937)$. We therefore present results for the main effects of abundance and time of arrival only. We also calculated response ratios and $95 \%$ confidence intervals for average survivorship after $68 \mathrm{~h}$ as per Borenstein et al. (2009).

We analyzed the behavior data to determine whether priority effects or settler abundance resulted in lemon 
damselfish displaying changes in: (1) aggressive interactions; (2) the avoidance of competitors; (3) changes in the distance ventured from the reef; or (4) relative height on the reef. For each response variable, we fit separate linear mixed-effects (LME) models that included settler abundance, time of arrival and their two-way interaction as fixed effects, and reef nested within temporal block as a random effect. We used maximum likelihood to estimate variance components (Venables and Ripley 2002) and selected the best-fit models as determined by AIC. In all cases, the best-fit model omitted an interaction between time of arrival and abundance $(P>0.05$ in all cases) and we therefore present results for the main effects of time of arrival and abundance only. All data met assumptions of homoscedasticity (in all cases $P>0.05$ for Levene's test of homogeneity of variance).

All statistical analyses were conducted using the statistical software R version 3.0.1 (R Development Core Team 2013). We used the survival library to fit Cox proportional hazard regressions and the library nlme to fit LMEs.

\section{Results and discussion}

By manipulating both priority effects and settler abundance, we showed that priority effects can have a larger influence on individual survival than the number of individuals arriving at a site. We found a strong inhibitory priority effect-lemon damselfish arriving $3 \mathrm{~h}$ later than Ambon damselfish experienced depressed survival $(P=0.015, \mathrm{CMR}=76 \%$; Fig. 1a, b), were less aggressive $\left(F_{(1,42)}=5.12, P=0.029 ;\right.$ Fig. $\left.2 \mathrm{a}\right)$ and were 2.7 times more likely to avoid competitive interactions $\left(F_{(1,42)}=8.011, P=0.007\right.$; Fig. 2 b) relative to when they arrived at the same time as Ambon damselfish. In contrast, increasing the abundance of lemon damselfish settlers from 2 to 6 individuals did not result in statistically significant effects on lemon damselfish mortality $(P=0.131$, $\mathrm{CMR}=52 \%$; Fig. 1a, b), aggression by lemon damselfish $\left(F_{(1,42)}=1.108, \quad P=0.299\right.$; Fig. 2 a) or avoidance by lemon damselfish $\left(F_{(1,42)}=0.664, P=0.419\right.$; Fig. $\left.2 b\right)$; however, these results may have partly be due to insufficient statistical power. After $68 \mathrm{~h}$, average survivorship of lemon damselfish at high abundance was $75 \%$ $(C I=46-125 \%)$ of that at low abundance, whereas average survivorship of late-arriving lemon damselfish was $56 \%(C I=33-92 \%)$ of that when lemon damselfish arrived simultaneously with Ambon damselfish.

Aggression of Ambon damselfish did not differ between treatments (timing: $F_{(1,42)}=1.923, P=0.173$; density: $\left.F_{(1,42)}=0.713, \quad P=0.403\right)$, suggesting that reduced aggression of late-arriving lemon damselfish was the result of submission to Ambon damselfish with concurrent decreases in survival. Previous work has found that competition increases the exposure of subordinate fish to predators due to displacement from refuge habitat (Carr et al. 2002; Holbrook and Schmitt 2002; Almany 2003). The inability to find (and defend) shelter sites may therefore explain decreased survival of late-arriving lemon damselfish in this study.

The influence of priority effects on the survival of lemon damselfish was approximately 1.5 times greater than that of variability in settler abundance, suggesting that for the species combinations and abundances used in this experiment, timing of arrival outweighs variation in settler abundance as the critical driver of early recruitment success. However, the general applicability of these results to other species and contexts requires further investigation. Although we had planned to examine for reciprocal effects between Ambon and lemon damselfish, we were limited in
Fig. 1 a Temporal trends in survival of focal lemon damselfish relative to timing of arrival (simultaneous or late for lemon damselfish) and the density of lemon damselfish (two individuals: gray symbols; six individuals: black symbols). Error bars are omitted for clarity. b Survival of lemon damselfish after 68 h. Error bars are 95\% confidence intervals
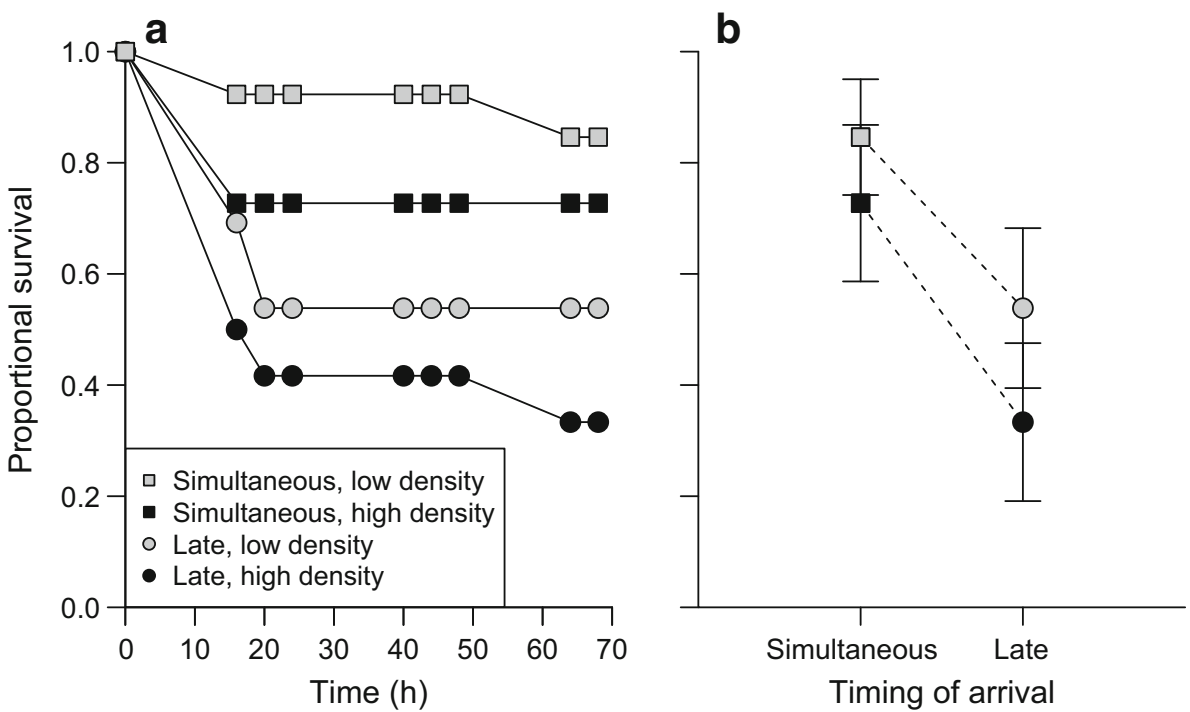

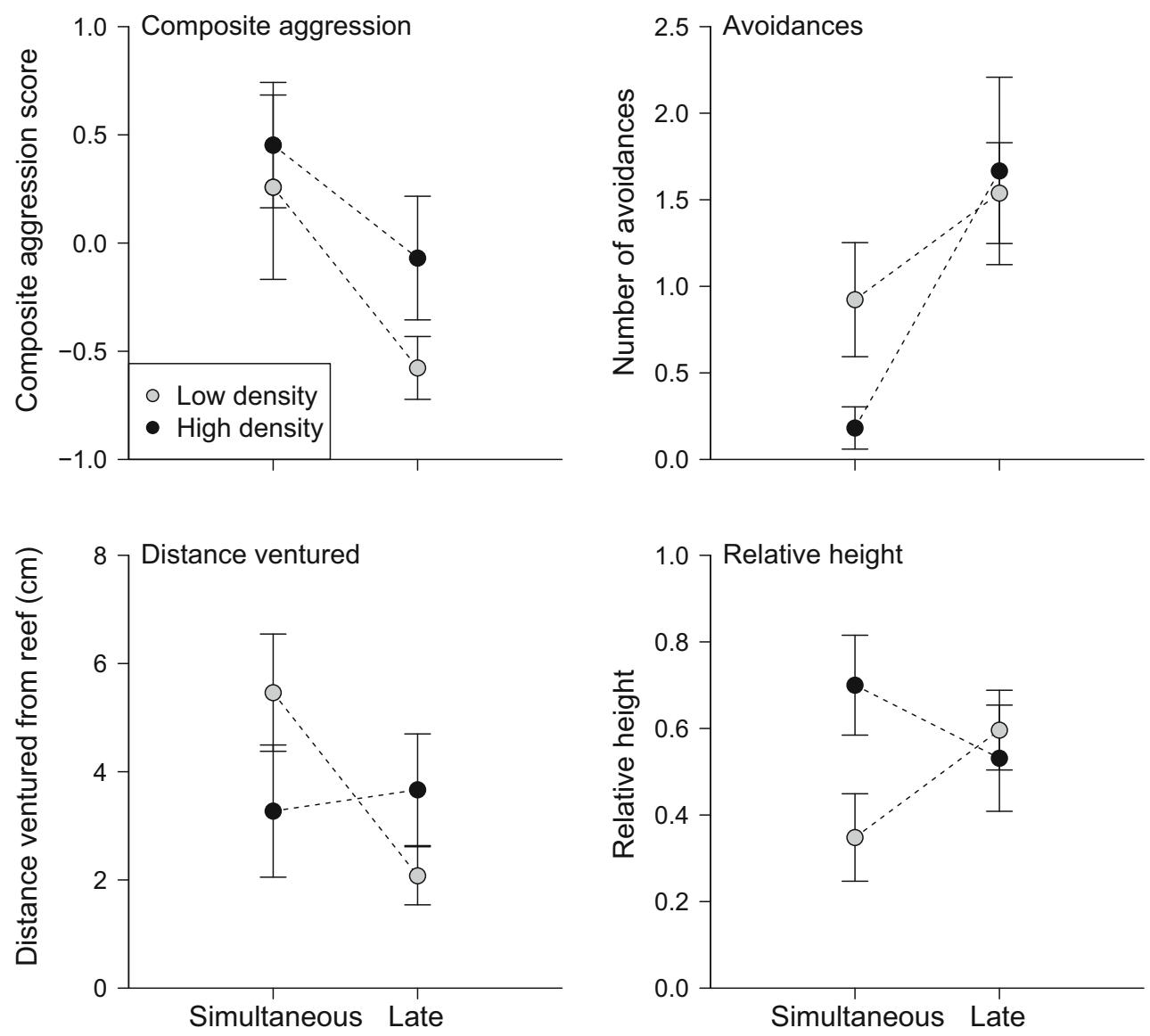

Fig. 2 Composite aggression scores (modeling chases and displays: see electronic supplementary material), number of avoidances, distance ventured from the reef and relative height on the reef (mean $\pm \mathrm{SE}$ ) of lemon damselfish relative to timing of arrival

our ability to do so due to low numbers of Ambon damselfish caught in light traps. If the results from this study are generally applicable, and priority effects have a strong influence on colonizer establishment, focusing on the number of colonizers without considering interactions between colonizers and established residents will likely reduce the accuracy of predictions of colonizer success, with potential implications for the management of fisheries yield, invasive species or restoration initiatives (e.g., Grman and Suding 2008; Dickson et al. 2012; Collie et al. 2013). Alternatively, if abundance has a stronger influence on colonizer success than priority effects, higher abundances of late-arriving individuals may either overwhelm established residents and mitigate the competitive advantage of early arrival (e.g., Gilpin and Case 1976) or enhance priority effects when predatory effort is focused on highly abundant prey (e.g., Webster and Almany 2002).

There is an emerging suggestion that the density of early-established populations is likely to have a strong impact on priority effects (e.g., Waters et al. 2013), and the results from our study highlight the requirement for

(simultaneous or late for lemon damselfish) and the density of lemon damselfish (two individuals: gray symbols; six individuals: black symbols)

additional research into the general importance of priority effects relative to the abundance of late-arriving individuals. Our results give rise to a number of future questions that relate to determining the role of reciprocal effects (including the sequence [who arrives first]) and timing [by how much] of arrival), the relationship between the intensity of priority effects and phylogenetic relatedness, and the effect that variation in the numbers of both early and late settlers has on individual survival. Answering these questions could lead to a better mechanistic understanding of population and community dynamics than numbers of colonizers alone.

Acknowledgments We would like to thank staff at the Lizard Island Research Station and B. Allan, C. Mirbach and C. Thompson for field assistance. Three anonymous reviewers provided many helpful comments on versions of this manuscript. This study was funded by the Ian Potter Foundation (D. E. Poulos) and an Australian Research Council Grant (M. I. McCormick). All applicable institutional and/or national guidelines for the care and use of animals were followed. Research was undertaken under the James Cook University Animal Ethics guidelines (Animal Ethics Approvals: A2080). 


\section{References}

Adam TC (2011) High quality habitat and facilitation ameliorate competitive effects of prior residents on new settlers. Oecologia 166:121-130

Almany GR (2003) Priority effects in coral reef fish communities. Ecology 84:1920-1935

Borenstein M, Hedges LV, Higgins JPT, Rothstein HR (2009) Introduction to meta-analysis. John Wiley \& Sons, United Kingdom

Carr MH, Anderson TW, Hixon MA (2002) Biodiversity, population regulation, and the stability of coral reef fish communities. Proc Natl Acad Sci U S A 99:11241-11245

Chesson P (2003) Quantifying and testing coexistence mechanisms arising from recruitment fluctuations. Theor Popul Biol 64:345-357

Collie J, Rochet MJ, Bell R (2013) Rebuilding fish communities: the ghost of fisheries past and the virtue of patience. Ecol Appl 23:374-391

Cox DR (1972) Regression models and life-tables. J R Stat Soc Series B Stat Methodol 34:187-220

Dickson TL, Hopwood JL, Wilsey BJ (2012) Do priority effects benefit invasive plants more than native plants? An experiment with six grassland species. Biol Invasions 14:2617-2624

Dufour V, Galzin R (1993) Colonisation patterns on reef fish larvae to the lagoon at Moorea Island, French Polynesia. Mar Ecol Prog Ser 102:143-152

Foster BL, Tilman D (2003) Seed limitation and the regulation of community structure in oak savanna grassland. $J$ Ecol 91:999-1007

Fukami T (2015) Historical contingency in community assembly: integrating niches, species pools, and priority effects. Annu Rev Ecol Evol Syst 46:1-23

Fukami T, Nakajima M (2011) Community assembly: alternative stable states or alternative transient states? Ecol Lett 14:973-984

Fukami T, Dickie IA, Wilkie JP, Paulus BC, Park D, Roberts A, Buchanan PK, Allen RB (2010) Assembly history dictates ecosystem functioning: evidence from wood decomposer communities. Ecol Lett 13:675-684

Gaines S, Roughgarden J (1985) Larval settlement rate: a leading determinant of structure in an ecological community of the marine intertidal zone. Proc Natl Acad Sci U S A 82:3707-3711

Geange SW, Stier AC (2009) Order of arrival affects competition in two reef fishes. Ecology 90:2868-2878

Geange SW, Stier AC (2010) Priority effects and habitat complexity affect the strength of competition. Oecologia 163:111-118

Gilpin ME, Case TJ (1976) Multiple domains of attraction in competition communities. Nature 261:40-42
Grman E, Suding KN (2008) Within-year soil legacies contribute to strong priority effects of exotics on native California grassland communities. Restoration Ecology 18:664-670

Holbrook SJ, Schmitt RJ (1997) Settlement patterns and processes in a coral reef damselfish: in situ nocturnal observations using infrared video. Proc 8th Int Coral Reef Symp 2:1143-1148

Holbrook SJ, Schmitt RJ (2002) Competition for shelter space causes density-dependent predation mortality in damselfishes. Ecology $83: 2855-2868$

Lande R, Engen S, Saether BE (2003) Stochastic population dynamics in ecology and conservation. Oxford University Press, Oxford, UK

Leibold MA, Holyoak M, Mouquet N, Amarasekare P, Chase JM, Hoopes MF, Holt RD, Shurin JB, Law R, Tilman D, Loreau M, Gonzalez M (2004) The metacommunity concept: a framework for multi-scale community ecology. Ecol Lett 7:601-613

McCormick MI (2009) Behaviourally mediated phenotypic selection in a disturbed coral reef environment. PLoS One 4:e7096

Munday PL (2004) Competitive coexistence of coral-dwelling fishes: the lottery hypothesis revisited. Ecology 85:623-628

Poulos DE, McCormick MI (2014) Who wins in the battle for space? The importance of priority, behavioural history and size. Anim Behav 90:305-314

Poulos DE, McCormick MI (2015) Asymmetries in body condition and order of arrival influence competitive ability and survival in a coral reef fish. Oecologia 179:719-728

Development Core Team R (2013) R: a language and environment for statistical computing. R Foundation for Statistical Computing, Vienna, Austria

Shima JS (2001) Regulation of local populations of a coral reef fish via joint effects of density- and number-dependent mortality. Oecologia 126:58-65

Shima JS, Osenberg CW (2003) Cryptic density dependence: effects of covariation between density and site quality in reef fish. Ecology 84:46-52

Steele MA (1997) Population regulation by post-settlement mortality in two temperate reef fishes. Oecologia 112:64-74

Venables WN, Ripley BD (2002) Modern applied statistics with S, 4 th edn. Springer, New York

Waters JM, Fraser CI, Hewitt GM (2013) Founder takes all: densitydependent processes structure biodiversity. Trends Ecol Evol 28:78-85

Webster MS, Almany GR (2002) Positive indirect effects in a coral reef fish community. Ecol Lett 5:549-557

Wilson WG, Lundberg P (2006) Non-neutral dynamics: empirical predictions for ecosystem function and diversity from linearized consumer-resource interactions. Oikos 114:71-83 


\section{Methods}

\section{Study species}

The Ambon and lemon damselfishes (Pomacentrus amboinensis and P. moluccensis, respectively) co-occur on shallow reefs throughout the Indo-Pacific. At Lizard Island, on the northern Great Barrier Reef, pelagic larvae of the Ambon and lemon damselfish colonize reef habitat in substantial numbers from October to February in a series of settlement pulses closely tied to lunar phases. Individuals of each species typically settle at a standard length (SL) of 9-14 mm (Kerrigan 1996) with their juvenile body plans largely complete (McCormick et al. 2002). Both species have similar habitat requirements at settlement and they are found in highest densities at the base of shallow reefs (McCormick et al. 2010; McCormick and Weaver 2012). The number of recently settled damselfish that reside on a patch reef can be high, and may reach up to 65 on a $0.125 \mathrm{~m}^{3}$ reef of mixed live and dead hard coral (McCormick and Hoey 2004). As individuals transition from the pelagic environment to shallow reefs, they encounter established residents and other recently settled individuals from the same cohort. Upon settlement, intra- and interspecific aggression is common within and between these species (Jones 1987; McCormick and Weaver 2012) as they endeavor to outcompete one another for limited resources.

\section{Study site}

The study was conducted in the lagoon of Lizard Island, Great Barrier Reef $\left(41^{\circ} 41.23^{\prime} \mathrm{S}\right.$, $145^{\circ} 27.17^{\prime} \mathrm{E}$ ) in January 2015 using a grid of 42 coral patch reefs in water approximately $3 \mathrm{~m}$ deep. Reefs were located on a sand flat, separated from one another by $3-4 \mathrm{~m}$ and from nearby natural reefs by a minimum of $10 \mathrm{~m}$. We constructed reefs to minimize habitat variation by standardizing size, rugosity and water depth. Each reef consisted of a 50:50 mixture of live and dead Pocillopora damicornis (a hard bushy coral) with a volume of approximately $0.07 \mathrm{~m}^{3}$. All resident fish species were removed at the start of the experiment using a dilute solution of eugenol (clove oil) and hand nets.

\section{Experimental design and execution}

To evaluate the relative strength of priority effects and settler abundance, and the degree to which they interact, we experimentally manipulated the abundance and timing of arrival of lemon damselfish settlers relative to those of the Ambon damselfish. We used settlement-stage 
fishes $(11.30 \pm 0.35 \mathrm{~mm} \mathrm{SL}[\mathrm{mean} \pm \mathrm{SD}])$ that were naïve in respect to interactions with reefbased predators and competitors. Settlement-stage fishes were captured in light traps moored overnight at Coconut Bay $\left(41^{\circ} 40.86^{\prime} \mathrm{S}, 145^{\circ} 28.43^{\prime} \mathrm{E}\right)$, approximately $2.5 \mathrm{~km}$ from the study reefs. Immediately after dawn collections, fish were transported to $25-\mathrm{L}$ flow-through aquaria where they were kept in single species groups and fed twice daily ad libitum with newly hatched Artemia sp. nauplii for 1-4 days. To allow the identification of experimental fish, each fish was tagged below the dorsal fin with subcutaneous fluorescent elastomer (VIE; Northwest Marine Technology, Shaw Island, Washington, USA) using a 27-gauge hypodermic needle. Tagging was done while holding fish within a $150 \mathrm{~mL}$ zip-lock bag of aerated seawater to minimize handling stress. No fish were tagged sooner than $12 \mathrm{~h}$ after collection. Tags were readable through the skin of the fish by observers in the field, so it was not necessary to recapture individuals to determine their identity. VIE tags do not have adverse effects on these or other fishes (Hoey and McCormick 2006; Simon 2007; Geange and Stier 2009) and have been used to tag fish as small as $8 \mathrm{~mm}$ (Frederick 1997). We therefore assume that tagging and handling effects were minimal. After tagging, we returned fish to flow-through aquaria for a recovery period of at least $12 \mathrm{~h}$ before measuring them to the nearest $0.1 \mathrm{~mm}$ SL with calipers through a zip-lock plastic bag filled with aerated seawater.

We simulated settlement pulses of naïve fishes between 0700 and 1100 hrs by introducing two Ambon damselfish onto patch reefs either simultaneously or $3 \mathrm{~h}$ before introducing either two or six lemon damselfish. We ran the experiment in five temporal blocks between 21 and 28 January 2015. Because temporal blocks overlapped, replicates were randomized across available reefs within the grid of 42 patch reefs, yielding 13 replicates for treatments 1 and 2, 11 replicates for treatment 3 and 12 replicates for treatment 4 . Our four treatments were: (1) low settler abundance without a priority effect (two Ambon and two lemon damselfish introduced simultaneously); (2) low settler abundance with a priority effect (two Ambon damselfish introduced $3 \mathrm{~h}$ before two lemon damselfish individuals); (3) high settler abundance without a priority effect (two Ambon and six lemon damselfish introduced simultaneously); and (4) high settler abundance with a priority effect (two Ambon damselfish introduced $3 \mathrm{~h}$ before six lemon damselfish). Simulated settlement pulses of 4-8 individuals are representative of the numbers of post-settlement fishes we observe on reefs of the size used in this study (D. Poulos pers. obs.). A 3-h priority period is ecologically relevant since reef fishes 
settle to the reef over several hours overnight (Dufour and Galzin 1993; Holbrook and Schmitt 1997), and previous studies have shown that competitive interactions are strongest in the hours immediately following settlement (Almany 2003; McCormick 2009; Poulos and McCormick 2014). For each reef, we sized-matched Ambon and lemon damselfish so that their SLs did not differ by more than $0.3 \mathrm{~mm}$, and tagged one individual of each species a different color to the rest of the group. These individuals acted as the focal individuals for behavioral observations and the analysis of survival, and all focal individuals were tagged the same color. We randomized replicates across the grid of 42 patch reefs in five temporal blocks between 21 and 28 January 2015, yielding 13 replicates for treatments 1 and 2, 11 replicates for treatment 3 and 12 replicates for treatment 4 .

To help gain a mechanistic understanding of the processes driving priority effects we conducted 3-min behavioral observations approximately $20 \mathrm{~min}$ after fish were added to reefs. Behavioral observations were adapted from McCormick 2009. After allowing fish to acclimate to the observer's presence, behavioral observations were conducted at a distance of approximately $2 \mathrm{~m}$ from the reef. Observations were recorded for the lemon damselfish that interacted the most frequently with other individuals. We recorded five response variables for each individual: (1) the number of displays (showing side to target and erecting dorsal and anal fins); (2) the number of chases towards the other individual, including those involving conspecifics and heterospecifics; (3) the number of avoidances of the other individual, including those involving conspecifics and heterospecifics; (4) the maximum distance ventured from the reef, visually estimated to the nearest $\mathrm{cm}$; and (5) relative height on the reef, which we summarized as a cumulative percentage of the time spent at varying heights on the reef over the observation period, with the top of the patch taken as a height of 1 , the middle of the patch taken as a height of 0.5 , and the bottom of the patch taken as 0 .

We surveyed reefs three times a day (at approximately 0800, 1200 and $1600 \mathrm{hrs)}$ for $3 \mathrm{~d}$ after we introduced lemon damselfish, recording survival of all individuals and removing any new, non-tagged Ambon or lemon damselfish settlers using eugenol and hand nets. We did not observe tagged individuals moving between reefs, and therefore assume that the disappearance of an experimental fish was due to mortality rather than migration.

\section{References}


Almany GR (2003) Priority effects in coral reef fish communities. Ecology 84:1920-1935

Dufour V, Galzin R (1993) Colonisation patterns on reef fish larvae to the lagoon at Moorea Island, French Polynesia. Mar Ecol Prog Ser 102:143-152

Frederick JL (1997) Evaluation of fluorescent elastomer injection as a method for marking small fish. Bull Mar Sci 61:399-408

Geange SW, Stier AC (2009) Order of arrival affects competition in two reef fishes. Ecology 90: 2868-2878

Hoey AS, McCormick MI (2006) Effects of subcutaneous fluorescent tags on the growth and survival of a newly settled coral reef fish, Pomacentrus amboinensis (Pomacentridae). Proc $10^{\text {th }}$ Int Coral Reef Symp 1:420-425

Holbrook SJ, Schmitt RJ (1997) Settlement patterns and processes in a coral reef damselfish: in situ nocturnal observations using infrared video. Proc $8^{\text {th }}$ Int Coral Reef Symp 2:11431148

Jones GP (1987) Some interactions between residents and recruits in two coral reef fishes. J Exp Mar Bio Ecol 114:169-182

Kerrigan BA (1996) Temporal patterns in size and condition at settlement in two tropical reef fishes (Pomacentridae: Pomacentrus amboinensis and P. nagasakiensis). Mar Ecol Prog Ser 135:27-41

McCormick MI (2009) Behaviourally mediated phenotypic selection in a disturbed coral reef environment. PLoS One 4:e7096

McCormick MI, Hoey AS (2004) Larval growth history determines juvenile growth and survival in a tropical marine fish. Oikos 106:225-242

McCormick MI, Weaver CJ (2012) It pays to be pushy: intracohort interference competition between two reef fishes. PloS One 7:e42590

McCormick MI, Makey L, Dufour V (2002) Comparative study of metamorphosis in tropical reef fishes. Mar Biol 141:841-853

McCormick MI, Moore J, Munday P (2010) Influence of habitat degradation on fish replenishment. Coral Reefs 29:537-546

Poulos DE, McCormick MI (2014) Who wins in the battle for space? The importance of priority, behavioural history and size. Anim Behav 90:305-314

Simon J (2007) Evaluation of marking European silver eels with visible implant elastomer tags and alcian blue. J Fish Biol 70:303-309 